\title{
Combination of clinical risk profile, early exercise testing and circulating biomarkers for evaluation of patients with acute chest pain without ST-segment deviation or troponin elevation
}

\author{
J Sanchis, ${ }^{1}$ X Bosch, ${ }^{2}$ V Bodí, ${ }^{1}$ N Bellera, ${ }^{2}$ J Núñez, ${ }^{1}$ B Benito, ${ }^{2} \mathrm{~J}$ Ordóñez, ${ }^{3}$ \\ L Consuegra, ${ }^{1} \mathrm{M} \mathrm{Heras,}^{2}$ À Llàcer ${ }^{1}$
}

${ }^{1}$ Servei de Cardiologia, Hospital Clínic Universitari, Universitat de València, València, Spain;

${ }^{2}$ Servei de Cardiologia, Hospital Clínic i Provincial, Barcelona

Spain; ${ }^{3}$ Departament de Bioquímica, Hospital de la Santa Creu i San Pau, Barcelona, Spain

Correspondence to: Dr J Sanchis, Servei de Cardiologia, Hospital Clinic Universitari, Blasco Ibáñez 17, 46010 València, Spain; sanchis juafor@gva.es

Accepted 23 May 2007 Published Online First 16 July 2007

\section{ABSTRACT}

Objective: To investigate the combination of clinical data, exercise testing and biomarkers for the evaluation of patients with chest pain without ST-segment deviation or troponin elevation.

Design: Prospective cohort design.

Settting: Two teaching hospitals in Spain.

Patients: 422 patients presenting to the emergency department were studied. Leukocyte count, C-reactive protein (CRP), pregnancy-associated plasma protein $A$ (PAPP-A) and N-terminal pro-brain natriuretic peptide (NTproBNP) were determined. A validated clinical risk score (number of points according to pain characteristics and risk factors) was used for clinical evaluation and early exercise testing was performed.

Main outcome measures: Adverse events (death, myocardial infarction or revascularisation) during a median 60 weeks follow-up.

Results: By receiver operating characteristic curve analysis, the association between death or myocardial infarction and adverse events was not significant with leukocyte count ( $p=0.3, p=0.3$ ) or CRP ( $p=0.5$, $p=0.8$ ), was borderline significant with PAPP-A $(p=0.07, p=0.04)$ and strongly significant with NT-proBNP ( $p=0.0001, p=0.0001)$. By Cox regression including clinical risk score, exercise testing result and biomarkers, exercise testing was the independent predictor of revascularisation $(p=0.0001)$, whereas risk score $(p=0.03)$ and NT-proBNP $(p=0.0004)$ predicted death or myocardial infarction. The inclusion of NT-proBNP improved the accuracy of the model for death or myocardial infarction (C-statistic 0.84 versus 0.76 , $p=0.01)$. The combination of clinical score and NTproBNP afforded the stratification in high $(17.2 \%$, $p=0.0001)$, intermediate $(5.3 \%)$ and low (1.1\%) risk categories of death or myocardial infarction.

Conclusions: NT-proBNP provides incremental prognostic information above that given by clinical history and exercise testing in patients with chest pain without STsegment deviation and negative troponin.

The prognostic role of biomarkers related to inflammation and ventricular dysfunction has been studied in acute coronary syndromes. ${ }^{1}$ Their predictive power seems to be additive: the greater the number of biomarkers elevated, the worse the prognosis. ${ }^{23}$ Beyond inflammation at the vascular wall level, inflammation or dysfunction at the area of myocardial necrosis could be the stimulus for biomarker elevation. In the absence of myocardial necrosis, however, the prognostic value is not fully clear.

Risk stratification of patients with acute chest pain and negative troponin is one of the most challenging tasks facing doctors in the emergency department. This is a heterogeneous population to include individuals without coronary artery disease and some with an acute coronary syndrome. The clinical history is often the only tool for evaluation and decision making because the electrocardiogram provides prognostic data, such as ST-segment deviation, in only $12 \%$ of cases in this setting. ${ }^{4}$ Therefore, biomarkers with an ability to identify high-risk patients have the potential to be a very useful, simple, and widely available tool.

In the present study we approached the risk stratification of the most challenging population: those with chest pain without ST-segment deviation or troponin elevation. To stratify patient risk, a strategy combining clinical history, early exercise testing and multimarker determination was used. For clinical evaluation, we applied a clinical risk score proved to have utility in this population. ${ }^{56}$ The biomarkers studied included white blood cell (WBC) count and C-reactive protein (CRP) as acute phase reactants, pregnancy-associated plasma protein A (PAPP-A) as a marker of plaque instability, and $\mathrm{N}$-terminal pro-brain natriuretic peptide (NT-proBNP) as a marker of left ventricular wall stress. The objective was to analyse whether a biomarker or a multimarker approach provides additional prognostic information to both a clinical risk profile and early exercise testing.

\section{METHODS}

\section{Study group}

From November 2003 to June 2005, 422 consecutive patients presenting with acute chest pain of possible coronary origin to the emergency department of the Hospital Clínic Universitari, Valencia, and Hospital Clínic i Provincial, Barcelona, were included. The inclusion criterion was the clinical diagnosis of chest pain of possible coronary origin, established by the cardiologist on duty. All patients were evaluated by a chest pain unit protocol implemented in both institutions. This protocol has been described previously. ${ }^{4-8}$ The procedure involves an evaluation of clinical history, electrocardiogram (ST-segment deviation considered if $\geqslant 1 \mathrm{~mm}$ ), serial troponin I levels (determined on arrival and eight and 12 hours after pain onset) and 
early exercise testing in patients with the ability to exercise using a symptom-limited Bruce protocol. Measurement of troponin I was performed at each institution and positive and negative values for myocardial infarction were assigned according to European Society of Cardiology/American College of Cardiology recommendations. ${ }^{9}$ Troponin I was determined using a heterogeneous immunoassay module (Dade Behring, Newark, USA) and troponin I elevation was defined as a level of $0.2 \mathrm{ng} / \mathrm{ml}$ or greater. The precision of the troponin threshold was confirmed by our laboratory, the coefficient of variation being less than $10 \%$.

After the initial evaluation, patients with a previous history of non-ischaemic heart disease, ST-segment deviation at admission, and troponin elevation in any determination, were excluded. Concomitant infections, known inflammatory or malignant diseases and suspected impaired renal function (creatinine $>1.5 \mathrm{mg} / \mathrm{dl}$ ) were also exclusion criteria. Within the first 24 hours of patient arrival, but after ruling out troponin elevation at 12 hours of pain onset, a blood sample was obtained for CRP, PAPP-A and NT-proBNP determination.

\section{Clinical evaluation}

The clinical characteristics of chest pain presentation and risk factors were assessed. On the basis of pain characteristics, the semiquantitative index previously reported by Geleijnse et al ${ }^{10}$ was calculated. This consists of a predefined questionnaire to evaluate the clinical characteristics of pain presentation and has been proved to be associated with the outcome of patients with acute chest pain. ${ }^{5}$

The risk profile of the patient population was established by applying a previously validated risk score. ${ }^{56}$ This score was designed for patients with acute chest pain without ST-segment deviation or troponin elevation, and included five variables independently related to the risk of death or myocardial infarction at one year: typical presentation of the chest pain (if $\geqslant 10$ points on the Geleijnse questionnaire); two or more pain episodes in the past 24 hours; age 67 years or more; insulindependent diabetes mellitus and previous coronary angioplasty. One point was assigned to each variable except insulindependent diabetes, which was assigned 2 points because its hazard ratio (HR) was twofold greater.

\section{Blood markers testing}

WBC were counted at each institution at admission. For the measurement of CRP, PAPP-A and NT-proBNP, a blood sample was drawn during the first 24 hours of patient admission and serum was separated and stored at $-80^{\circ} \mathrm{C}$ until processed. The determination of markers other than WBC was performed in a blinded manner at the Biochemistry Department of the Hospital de la Santa Creu i San Pau, Barcelona. For CRP measurement, a high-sensitivity, particle-enhanced immunoturbidimetric assay (Tina-Quant ultrasensitive PCR latex; Roche Diagnostics, Mannheim, Germany) with a measurement range of 0.1 to $20 \mathrm{mg} / \mathrm{l}$ was used in an Hitachi 911 analyser. PAPP-A was measured by an ultrasensitive ELISA method (Diagnostics System Laboratories, Webster, Texas, USA). The assay is an enzymatically amplified, two-step sandwich-type immunoassay using monoclonal antibodies against the PAPP-A molecule, but not against the pro-major basic protein subunit. The stated detection limit and maximal between-batch variance are $0.06 \mathrm{mU} / 1$ and $9.8 \%$, respectively. NT-proBNP was measured by a commercially available electrochemiluminescence immunoassay based on the use of a pair of polyclonal anti-NT-proBNP antibodies, one biotinylated and the other labelled with a ruthenium complex (Roche Diagnostics, Mannheim, Germany). The between-batch variance ranged from $5.5 \%$ to $7.3 \%$ for concentrations from 185 to $12300 \mathrm{ng} / \mathrm{l}$ on an Elecsys 2010 analyser.

\section{Endpoints}

The median follow-up was 60 weeks (interquartile interval 4686 weeks). Adverse events (all-cause mortality, acute myocardial infarction or revascularisation) were recorded. An acute myocardial infarction was defined as a new episode of chest pain with an increased troponin I. Acute myocardial infarction was also considered if creatine kinase $M B$ mass increased to three or more times after percutaneous transluminal coronary angioplasty or to five or more times the upper limit of reference after coronary bypass surgery, respectively. Creatine kinase $M B$ mass $(5 \mu \mathrm{g} / \mathrm{l}$ was used as the upper reference limit) was routinely determined at 12 and 24 hours after a revascularisation procedure.

Four patients were excluded from the final analysis as a result of missing blood samples for NT-proBNP determination.

\section{Statistical analysis}

The association between blood markers and outcomes was tested by univariate analysis using receiver operating characteristic curves. Likewise, the patient population was categorised according to the clinical risk score into high ( $\geqslant 3$ points), intermediate ( 2 points) and low ( $0-1$ points) risk categories, and according to the exercise result into negative, positive, inconclusive and inability to exercise categories. The differences between the categories in blood marker levels, using the MannWhitney U non-parametric test, and in outcomes, using the chisquare test, were analysed.

A multivariate analysis by Cox regression models tested the independent relation of clinical risk score category, early exercise testing category and blood markers with the outcomes. First, a multivariable model introducing clinical risk score and early exercise testing categories was calculated. Second, those biomarkers showing $\mathrm{p}<0.1$ in the univariate analysis were introduced into the model. Blood markers were log-transformed to improve the normality of distribution. Calculations were

Table 1 Characteristics of the patient population $(n=422)$

\begin{tabular}{lr}
\hline Pain score $\geqslant 10$ points & $174(41 \%)$ \\
Age (years) & $63(12 \mathrm{SD})$ \\
$\geqslant 2$ Pain episodes in $<24$ hours & $120(28 \%)$ \\
Killip $>1$ at presentation & $7(2 \%)$ \\
Male & $265(63 \%)$ \\
Smokers & $105(25 \%)$ \\
Arterial hypertension & $105(25 \%)$ \\
Hypercholesterolemia & $212(50 \%)$ \\
Diabetes mellitus & $96(23 \%)$ \\
Family history of ischaemic heart disease & $41(10 \%)$ \\
Previous myocardial infarction & $105(25 \%)$ \\
Previous PTCA & $77(18 \%)$ \\
Previous CABG & $44(10 \%)$ \\
Previous heart failure & $7(2 \%)$ \\
Previous stroke & $22(5 \%)$ \\
Previous peripheral artery disease & $36(9 \%)$ \\
Previous aspirin treatment & $182(43 \%)$ \\
Previous statin treatment & $171(41 \%)$ \\
\hline
\end{tabular}

CABG, Coronary artery bypass graft; PTCA, percutaneous transluminal coronary angioplasty. 
performed using SPSS software version 9.0 (Chicago, Illinois, USA).

\section{RESULTS}

\section{Patient population and management}

Table 1 shows the characteristics of the patient population. A total of 320 patients $(76 \%)$ were eligible for early exercise testing (within the first 24 hours after arrival). All 179 patients with a negative result were discharged after the exercise test, whereas all 48 with a positive test were hospitalised. In the case of an inconclusive test, patients who reached at least 5 METS equivalents were also discharged.

The remaining 102 patients with contraindication to exercise (physical incapacity or abnormalities in the baseline electrocardiogram) were hospitalised for further evaluation. Their management was left at the discretion of the attending doctor. Sixteen patients underwent cardiac magnetic resonance with dipyridamole and 68 cardiac catheterisation.

Overall, 250 (59\%) patients were discharged early and 172 (41\%) were hospitalised. During hospitalisation, 105 patients underwent cardiac catheterisation, 40 coronary angioplasty and nine coronary bypass surgery.

Throughout the follow-up, seven (1.7\%) patients died, 21 $(5 \%)$ died or suffered an acute myocardial infarction and 64 $(15.2 \%)$ were revascularised. A total of 74 patients $(17.5 \%)$ presented with adverse events.

\section{Blood markers and outcomes}

The median values and interquartile ranges of biomarkers were: WBC count 7650 cells/ml (6200-9225), CRP $3.6 \mathrm{mg} / 1$ (1.7-7.6), PAPP-A $1.2 \mathrm{mU} / 1$ (0.6-2.5) and NT-pro-BNP $110 \mathrm{ng} / \mathrm{l}$ (38-311). The area under the receiver operating characteristic curve (AUC) and its significance for each biomarker according to the outcomes were calculated. WBC count and CRP were not related to death or acute myocardial infarction (AUC 0.43, $p=0.3$; and AUC 0.46, $p=0.5$ ), or adverse events (AUC 0.54, $p=0.3$; and AUC 0.49, $\mathrm{p}=0.8$ ). PAPP-A showed a trend towards being associated with death or acute myocardial infarction (AUC 0.62, $p=0.07$ ) and was significantly associated with adverse events (AUC 0.58, p =0.04), whereas NT-pro-BNP was strongly associated with both endpoints (AUC 0.78, $\mathrm{p}=0.0001$; and AUC 0.65, $\mathrm{p}=0.0001$ ).

\section{Clinical risk profile}

The distribution of patients among the risk categories according to the clinical risk score was as follows: 236 patients with $0-1$ points, 104 with 2 points and 82 with 3 or more points. The distribution of the blood markers between risk categories was analysed (median values and interquartile range). There were no differences in WBC count $(p=1)$, CRP $(p=0.6)$ and PAPP-A $(p=0.2)$. Patients with $0-1$ points had lower NT-proBNP levels
(61 ng/l, 28 to 173, $\mathrm{p}=0.0001$ ) than patients with 2 points (186 ng/l, 84 to 404 ) or 3 points (282 ng/l, 83 to 771).

The frequency of death or acute myocardial infarction was greater in patients with 3 or more points $(13.1 \%, p=0.0001)$ than in patients with 2 points $(1.9 \%)$ or 1 or 0 points $(3.4 \%)$. Similarly, the frequency of adverse events was greater in patients with 3 or more points $(31.7 \%, p=0.0001)$ compared with patients with 2 points (23.1\%) and 0 or 1 point $(10.2 \%)$.

\section{Early exercise testing}

The distribution of biomarker levels into the subgroups according to the results of exercise testing showed no differences in leukocyte count, whereas patients with an inability to exercise had higher levels of CRP $(p=0.002)$, PAPP-A $(p=0.05)$ and NT-proBNP $(p=0.0001)$. The differences between the subgroups with positive and negative exercise test results were only significant for NT-proBNP: $189 \mathrm{ng} / 1$ (54 to 531) versus $59 \mathrm{ng} / \mathrm{l}$ (28 to 151), $\mathrm{p}=0.001$.

Patients with an inability to exercise exhibited the highest rate of death or myocardial infarction (10.8\%, $p=0.005)$ compared with the remaining categories (inconclusive $6.5 \%$, positive $2.1 \%$ and negative $1.7 \%$ ). In terms of adverse events, patients with a negative exercise test had the lowest rate $(2.2 \%$, $p=0.0001)$ compared with patients with a positive $(29.2 \%)$ or inconclusive $(17.2 \%)$ result, or the inability to exercise $(39.2 \%)$.

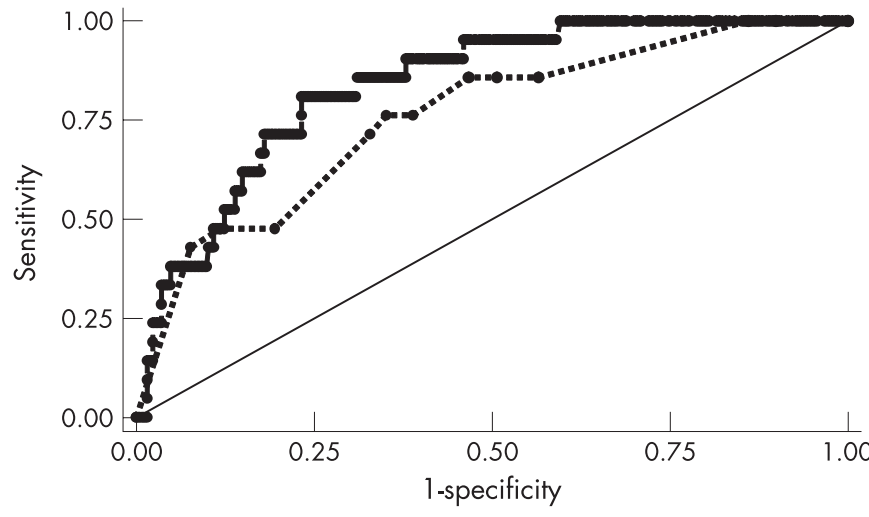

........ Clinical risk score + exercise test: AUC: 0.76

Clinical risk score + exercise test + NT-proBNP: AUC: 0.84

Figure 1 Receiver operating characteristic curves for the prediction of death or myocardial infarction. Dotted line, multivariable model including clinical risk score and early exercise result. Continuous line, multivariable model after adding N-terminal pro-brain natriuretic peptide (NT-proBNP). The model with NT-proBNP was significantly more accurate (C-statistic 0.84 versus $0.76, p=0.01)$. AUC, area under the receiver operating characteristic curve.

Table 2 Multivariable models for prediction of death or myocardial infarction

\begin{tabular}{llll}
\hline & $\mathbf{p}$ & HR (95\% CI) & C-index \\
\hline $\begin{array}{l}\text { Model without biomarkers } \\
\text { Clinical risk score }\end{array}$ & 0.01 & $2.9^{*}(1.1$ to 7.8$)$ & 0.76 \\
$\quad$ Exercise testing & 0.04 & $4.6^{* *}(1.2$ to 17.6$)$ & 0.84 \\
$\begin{array}{l}\text { Model with biomarkers } \\
\text { Clinical risk score }\end{array}$ & 0.03 & $2.8^{*}(1.1$ to 7.0$)$ & $1.8(1.3$ to 2.5$)$ \\
NT-proBNP & 0.0004 & & \\
PAPP-A & 0.1 & & \\
Exercise testing & 0.3 & & \\
\hline
\end{tabular}

HR, Hazard ratio; NT-proBNP, N-terminal pro-brain natriuretic peptide; PAPP-A, pregnancy-associated plasma protein A.

${ }^{*} \geqslant 3$ Points versus $<3$ points. ${ }^{* *}$ inability to exercise versus negative result. 


\section{Multivariable analysis}

Table 2 shows the results of the multivariate analysis. In the first model both clinical risk profile $(p=0.01)$ and exercise testing result $(p=0.04)$ had a predictive value for death or myocardial infarction, with a C-statistic of 0.76 . After adding the biomarkers, however, NT-proBNP $(p=0.0004)$ and clinical risk score category $(p=0.03)$ were the most important predictors, whereas PAPP-A $(p=0.1)$ showed a non-significant trend and exercise testing result $(p=0.3)$ lacked prognostic significance. The model, after adding NT-proBNP, was significantly more accurate than the model including only clinical risk score and exercise testing (C-statistic 0.84 versus 0.76 , $\mathrm{p}=0.01$; fig 1 ).

With regard to adverse events, exercise testing category was the independent predictor of adverse events $(p=0.0001)$, mostly because of its strong association with revascularisation $(p=0.0001)$. Risk score category had a non-significant tendency to be associated with adverse events $(p=0.1)$. The C-statistic of the model was 0.79 . The addition of NT-proBNP $(p=0.3)$ and PAPP-A $(p=0.5)$ did not increase the accuracy of the model.

\section{Stratification using the clinical risk score and NT-pro-BNP}

The cutoff values of 3 points or greater for the risk score and more than $110 \mathrm{ng} / 1$ for NT-proBNP were selected for predicting death or myocardial infarction. This NT-proBNP cutoff was chosen because it was the median value of the population and, in addition, showed evidence of high sensitivity (86\%) and a negative predictive value (99\%).

By Cox regression analysis, a risk score of 3 points or greater and NT-proBNP greater than $110 \mathrm{ng} / \mathrm{l}$ were associated with death or myocardial infarction (HR 3.7, 95\% confidence interval (CI) 1.5 to $8.9, p=0.003$; and $\mathrm{HR} 4.6,95 \%$ CI 1.3 to 16.1 , $p=0.02$ ). Table 3 presents the outcomes of the subgroups according to the risk score and NT-proBNP. The subgroup with a risk score of 3 points or greater and NT-pro-BNP greater than $110 \mathrm{ng} / \mathrm{l}$ had the highest incidence of death or myocardial infarction (10 of 58 patients, $17.2 \%, p=0.0001$ ). In contrast, the lowest risk subgroup (risk score less than 3 points and NT-proBNP less than $110 \mathrm{ng} / \mathrm{l}$ ) exhibited a very low rate of death or myocardial infarction (two out of 189 patients, 1.1\%). In the intermediate risk subgroup (risk score 3 points or greater or NTpro-BNP greater than $110 \mathrm{ng} / \mathrm{l}$ ) the frequency of death or myocardial infarction was also intermediate (nine out of 171 patients, $5.3 \%$ ).

\section{DISCUSSION}

The results of this study indicate that NT-proBNP provides incremental prognostic information above that given by clinical history and early exercise testing, in patients presenting in the emergency department with acute chest pain without STsegment deviation or troponin elevation.

Table 3 Subgroups of patients and outcomes according to the risk score and NT-proBNP

\begin{tabular}{lc}
\hline Subgroups & Death/AMI \\
\hline Risk score $\geqslant 3$ and NT-proBNP $>110$ & $17.2 \%(10 / 58)$ \\
Risk score $\geqslant 3$ and NT-proBNP $<110$ & $4.2 \%(1 / 24)$ \\
Risk score $<3$ and NT-proBNP $>110$ & $5.4 \%(8 / 147)$ \\
Risk score $<3$ and NT-proBNP $<110$ & $1.1 \%(2 / 189)$ \\
\hline
\end{tabular}

AMI, acute myocardial infarction; NT-proBNP, N-terminal pro-brain natriuretic peptide.

\section{Clinical history and exercise testing}

Chest pain without ischaemic changes in the electrocardiogram or troponin elevation constitutes a heterogeneous population that are challenging to stratify. Given the paucity of data for decision making, a meticulous clinical evaluation is of utmost importance. In a previous study we described a clinical risk score, using pain characteristics and risk factors, for the prognostic stratification of these patients. ${ }^{5}$ This score was applied in the present study, which included a mixed cohort from two centres, and confirmed its association with outcomes. The approach combining clinical profile and NT-proBNP, however, increased the accuracy of the prediction model and afforded the distinction of a wider spectrum of risk categories.

Early exercise testing constitutes a very useful tool for the evaluation of patients with acute chest pain. ${ }^{811} 12$ Its main contribution is that a negative result predicts a good outcome. The main disadvantages are that a proportion of patients are not able to exercise, and the existence of false-positive or inconclusive results. Furthermore, the logistic requirements may impede a 24 hour/seven-day access. In this sense, a simple biomarker determination seems to be an attractive tool. In the present study we have demonstrated the incremental prognostic value of NT-proBNP. Although exercise testing was the most important determinant of adverse events, because of its strong relation with revascularisation, NT-proBNP provided better additional prognostic information than exercise testing to clinical data for death or myocardial infarction. The main contribution of NT-proBNP seems to be the identification of high-risk patients, such as those with a high clinical risk profile and high levels of NT-proBNP, a condition that may be important in settings in which an early exercise test could not be performed. Nevertheless, the usefulness of NT-proBNP in those patients with a low risk profile and who can undergo exercise testing needs to be clarified in a larger cohort.

\section{N-terminal pro-brain natriuretic peptide}

Increased levels of brain natriuretic peptide and NT-proBNP imply a worse prognosis in the whole spectrum of acute coronary syndromes. ${ }^{13-17}$ The predictive value persisted in the subgroup of patients with unstable angina and negative troponin of the OPUS-TIMI 16 and PRISM trials performed in patients with non-ST-segment elevation acute coronary syndromes. ${ }^{13} 16$ NT-proBNP has, however, not been studied previously in less selected patients with chest pain without overt signs of acute coronary syndrome. Our results showed that NT-proBNP also predicted the outcome in this challenging population. We determined NT-proBNP within the first 24 hours of patient arrival, after ruling out troponin elevation. In other studies, such a determination was done as early as at arrival or as late as at 40 hours after admission. ${ }^{13}{ }^{17}$ In acute coronary syndromes, NT-proBNP levels have been shown in a previous study to have a dynamic behaviour with peak values at 16 to 24 hours after admittance. ${ }^{18}$ Therefore, sampling late after patient arrival but within the first 24 hours could be representative for risk assessment.

\section{Other biomarkers}

An increase in PAPP-A was related to a worse outcome in patients with acute coronary syndromes. ${ }^{19}{ }^{20}$ In other studies, however, PAPP-A was only a modest predictor. ${ }^{21}$ In the present study including patients with chest pain and normal troponin, although PAPP-A showed a trend towards association with a worse outcome, NT-proBNP was the best predictor. Lund et al ${ }^{19}$ 
and Heeschen et $a^{20}$ reported the association between PAPP-A and prognosis in patients with chest pain and normal troponin. The design of those studies, however, differed from our study: (1) ST-segment deviation was not an exclusion criterion, therefore the risk of the population could be different; (2) neither a risk score nor NT-proBNP was used; (3) the blood samples were taken at different times. The best time for PAPP-A determination remains to be elucidated. ${ }^{22}$ Finally, methodological issues such as whether PAPP-A antibodies used in the assays recognise the PAPP-A form released in acute coronary syndromes could also contribute to the differences between current data and others. ${ }^{23}$

CRP and WBC count are well-known prognostic markers in acute coronary syndromes. In chest pain patients with nonelevated troponin, however, some data have suggested a prognostic value, but other studies have not. ${ }^{19}{ }^{24-26}$ We did not find a significant association between CRP or WBC count and outcomes. The fact that myocardial necrosis is the most powerful stimulus for an increase in CRP could explain the loss of its prognostic significance in a normal troponin population. ${ }^{27}{ }^{28}$ In a recent series of patients with acute chest pain and non-elevated troponin, the WBC count also failed to predict outcomes. ${ }^{29}$

\section{CONCLUSIONS}

Risk stratification of patients with acute chest pain without STsegment deviation and negative troponin can be conducted combining the clinical history, early exercise testing and NTproBNP levels. The information provided by NT-proBNP is additional to that of the clinical history and early exercise testing for the prediction of death or myocardial infarction. Recognising how difficult it is to achieve effective risk stratification of individual patients with respect to multifactorial disease processes, ${ }^{30}$ the results of the present study suggest that the implementation of NT-proBNP in the emergency department could help decision making in this challenging population.

Funding: This work was supported by a grant Pfizer-2004 from the Spanish Society of Cardiology (Madrid, Spain) and a grant from HERACLES-FIS (Ministerio de Sanidad y Consumo, Madrid, Spain). JS, VB, JN and AL were also supported by a grant FIS PI070640 (Ministerio de Sanidad y Consumo, Madrid, Spain) and XB was supported by a grant FIS PI0500120 (Ministerio de Sanidad y Consumo, Spain).

Competing interests: None declared.

\section{REFERENCES}

1. Jaffe AS, Babuin L, Apple FS. Biomarkers in acute cardiac disease. The present and the future. J Am Coll Cardiol 2006:48:1-11.

2. Sabatine MS, Morrow DA, de Lemos JA, et al. Multimarker approach to risk stratification in non-ST-elevation acute coronary syndromes. Simultaneous assessment of troponin I, C-reactive protein and B-type natriuretic peptide. Circulation 2002;105:1760-3.

3. Bodí V, Sanchis J, Llàcer A, et al. Multimarker risk strategy for predicting 1-month and 1 -year major events in non-ST elevation acute coronary syndromes. Am Heart $J$ 2005; 149:268-74.

4. Sanchis J, Bodí V, Llácer A, et al. Risk stratification of patients with acute chest pain and normal troponin concentrations. Heart 2005;91:1013-18

5. Sanchis J, Bodí V, Núñez J, et al. New risk score for patients with acute chest pain, non-ST-segment deviation, and normal troponin concentrations: a comparison with the TIMI risk score. J Am Coll Cardiol 2005;46:443-9.

6. Sanchis J, Bodí V, Núñez J, et al. A practical approach with outcome for the prognostic assessment of non-ST-segment elevation chest pain and normal troponin. Am J Cardiol 2007;99:797-801.
7. Sanchis J, Bodí V, Llácer A, et al. Emergency room risk stratification of patients with chest pain without ST-segment elevation. Rev Esp Cardiol 2003;56:955-62.

8. Sanchis J, Bodí V, Núñez J, et al. Usefulness of early exercise testing and clinical risk score for prognostic evaluation in chest pain units without preexisting evidence of myocardial ischemia. Am J Cardiol 2006;97:633-5.

9. The Joint European Society of Cardiology/American College of Cardiology Committee. Myocardial infarction redefined. A consensus document of the joint European Society of Cardiology/American College of Cardiology Committee for the redefinition of myocardial infarction. J Am Coll Cardiol 2000;36:959-69.

10. Geleijnse ML, Elhendy A, Kasprzak JD, et al. Safety and prognostic value of early dobutamine-atropine stress echocardiography in patients with spontaneous chest pain and a non-diagnostic electrocardiogram. Eur Heart J 2000;21:397-406.

11. Defilippi ChR, Rosanio S, Tocchi M, et al. Randomized comparison of a strategy of predischarge coronary angiography versus exercise testing in low-risk patients in a chest pain-unit: in-hospital and long-term outcomes. J Am Coll Cardiol 2001;37:2042-9.

12. Amsterdam EA, Kirk JD, Diercks DB, et al. Immediate exercise testing to evaluate low-risk patients presenting to the emergency department with chest pain. J Am Coll Cardiol 2002; 40:251-6.

13. De Lemos JA, Morrow DA, Bentley JH, et al. The prognostic value of B-type natriuretic peptide in patients with acute coronary syndromes. N Engl J Med 2001;345:1014-21.

14. Jernberg $\mathbf{T}$, Stridsberg $M$, Venge $\mathrm{P}$, et al. N-terminal pro brain natriuretic peptide on admission for early risk stratification of patients with chest pain and no ST-segment elevation. J Am Coll Cardiol 2002:40:437-45.

15. Morrow DA, de Lemos JA, Sabatine MS, et al. Evaluation of B-type natriuretic peptide for risk assessment in unstable angina/non-ST-elevation myocardial infarction. B-type natriuretic peptide and prognosis in TACTICS-TIMI 18. J Am Coll Cardiol 2003;41:1262-72.

16. Heeschen $\mathbf{C h}, \mathbf{H a m m} \mathbf{C h W}$, Mitrovic V, et al. N-terminal pro-B-type natriuretic peptide levels for dynamic risk stratification of patients with acute coronary syndromes. Circulation 2004;110:3206-12.

17. Galvani M, Ottani F, Oltrona L, et al. N-terminal pro-brain natriuretic peptide on admission has prognostic value across the whole spectrum of acute coronary syndromes. Circulation 2004;110:128-34.

18. Riezebos RK, Ronner E, de Boer RA, et al. Dynamics in N-terminal pro-brain natriuretic peptide concentration in patients with non-ST-elevation acute coronary syndrome. Am Heart J 2005;150:1255-9.

19. Lund J, Qin $Q P, H v a T$, et al. Circulating pregnancy-associated plasma protein A predicts outcome in patients with acute coronary syndrome but no troponin I elevation. Circulation 2003;108:1924-6.

20. Heeschen Ch, Dimmeler S, Hamm ChW, et al. Pregnancy-associated plasma protein A levels in patients with acute coronary syndromes. Comparison with markers of systemic inflammation, platelet activation and myocardial necrosis. J Am Coll Cardiol 2005;45:229-37.

21. Laterza OF, Cameron SJ, Chappel D, et al. Evaluation of pregnancy-associated plasma protein $\mathrm{A}$ as a prognostic indicator in acute coronary syndrome. Clin Chim Acta 2004;348:163-69.

22. Qin Q-P, Laitinen P, Majamaa-Voltti K, et al. Release patterns of pregnancyassociated plasma protein A (PAPP-A) in patients with acute coronary syndromes. Scand Cardiovasc J 2002;36:358-61.

23. Quin $\mathbf{0}-\mathbf{P}$, Kokkala S, Lund J, et al. Immunoassays developed for pregnancyassociated plasma protein-A (PAPP-A in pregnancy may not recognize PAPP-A in acute coronary syndromes. Clin Chem 2006;52:398-404.

24. Brennan ML, Penn MS, Van Lente $F$, et al. Prognostic value of myeloperoxidase in patients with chest pain. N Engl J Med 2003;349:1595-604.

25. Lloyd-Jones DM, Camargo CA, Giugliano RP, et al. Effect of leukocytosis at initial examination on prognosis in patients with primary unstable angina. Am Heart $J$ 2001;139:867-73.

26. Furman MI, Gore JM, Anderson FA, et al. Elevated leukocyte count and adverse hospital events in patients with acute coronary syndromes: findings from the Global Registry of Acute Coronary Events (GRACE). Am Heart J 2004;147:42-8.

27. Cusack MR, Marber MS, Lambiase PD, et al. Systemic inflammation in unstable angina is the result of myocardial necrosis. J Am Coll Cardiol 2002;39:1917-23.

28. Sanchis $\mathbf{J}$, Bodí V, Llácer A, et al. Relationship of C-reactive protein levels with angiographic findings and markers of necrosis in non-ST-segment elevation acute coronary syndrome. Rev Esp Cardiol 2004;57:382-7.

29. Sanchis J, Bodí V, Núñez J, et al. Prognostic usefulness of white-blood cell count on admission and one-year outcome in patients with non-ST-segment elevation acute chest pain. Am J Cardiol 2006;98:885-9.

30. Ware JH. The limitations of risk factors as prognostic tools. N Engl J Med 2006;355:2615-17. 
HEART

\section{Combination of clinical risk profile, early exercise testing and circulating biomarkers for evaluation of patients with acute chest pain without ST-segment deviation or troponin elevation}

J Sanchis, X Bosch, V Bodí, et al.

Heart 2008 94: 311-315 originally published online July 16, 2007 doi: $10.1136 /$ hrt.2007.115626

Updated information and services can be found at:

http://heart.bmj.com/content/94/3/311.full.html

These include:

References This article cites 30 articles, 15 of which can be accessed free at: http://heart.bmj.com/content/94/3/311.full.html\#ref-list-1

Article cited in:

http://heart.bmj.com/content/94/3/311.full.html\#related-urls

Email alerting Receive free email alerts when new articles cite this article. Sign up in service the box at the top right corner of the online article.

Topic Articles on similar topics can be found in the following collections Collections

Notes

To request permissions go to:

http://group.bmj.com/group/rights-licensing/permissions

To order reprints go to:

http://journals.bmj.com/cgi/reprintform

To subscribe to BMJ go to:

http://group.bmj.com/subscribe/ 